\title{
Article \\ Effect of CO Molecule Orientation on the Reduction of Cu-Based Nanoparticles
}

\author{
Sergey Y. Sarvadii *, Andrey K. Gatin, Vasiliy A. Kharitonov, Nadezhda V. Dokhlikova, Sergey A. Ozerin, \\ Maxim V. Grishin and Boris R. Shub
}

Citation: Sarvadii, S.Y.; Gatin, A.K.; Kharitonov, V.A.; Dokhlikova, N.V.; Ozerin, S.A.; Grishin, M.V.; Shub, B.R Effect of CO Molecule Orientation on the Reduction of Cu-Based Nanoparticles. Nanomaterials 2021, 11, 279. https://doi.org/10.3390/ nano11020279

Academic Editor:

Nikolaos Dimitratos

Received: 22 December 2020

Accepted: 20 January 2021

Published: 22 January 2021

Publisher's Note: MDPI stays neutral with regard to jurisdictional claims in published maps and institutional affiliations.

Copyright: (c) 2021 by the authors. Licensee MDPI, Basel, Switzerland. This article is an open access article distributed under the terms and conditions of the Creative Commons Attribution (CC BY) license (https:/ / creativecommons.org/licenses/by/ $4.0 /)$.
N.N. Semenov Federal Research Center for Chemical Physics, Russian Academy of Sciences (FRCCP RAS), Kosygina str. 4, 119991 Moscow, Russia; akgatin@yandex.ru (A.K.G.); vch.ost@mail.ru (V.A.K.); dohlikovanv@gmail.com (N.V.D.); sergeoz@yandex.ru (S.A.O.); mvgrishin68@yandex.ru (M.V.G.); bshub@mail.ru (B.R.S.)

* Correspondence: sarvadiy15@mail.ru

\begin{abstract}
The adsorption of $\mathrm{CO}$ on the surface of $\mathrm{Cu}$-based nanoparticles was studied in the presence of an external electric field by means of scanning tunneling microscopy (STM) and spectroscopy (STS). Nanoparticles were synthesized on the surface of a graphite support by the impregnationprecipitation method. The chemical composition of the surface of the nanoparticles was determined as a mixture of $\mathrm{Cu}_{2} \mathrm{O}, \mathrm{Cu}_{4} \mathrm{O}_{3}$ and $\mathrm{CuO}$ oxides. $\mathrm{CO}$ was adsorbed from the gas phase onto the surface of the nanoparticles. During the adsorption process, the potential differences $\Delta V=+1$ or $-1 \mathrm{~V}$ were applied to the vacuum gap between the sample and the grounded tip. Thus, the system of the STM tip and sample surface formed an asymmetric capacitor, inside which an inhomogeneous electric field existed. The $\mathrm{CO}$ adsorption process is accompanied by the partial reduction of nanoparticles. Due to the orientation of the CO molecule in the electric field, the reduction was weak in the case of a positive potential difference, while in the case of a negative potential difference, the reduction rate increased significantly. The ability to control the adsorption process of $\mathrm{CO}$ by means of an external electric field was demonstrated. The size of the nanoparticle was shown to be the key factor affecting the adsorption process, and particularly, the strength of the local electric field close to the nanoparticle surface.
\end{abstract}

Keywords: copper oxides; $\mathrm{CO}$ adsorption; reduction; electric field; scanning tunneling microscopy; scanning tunneling spectroscopy

\section{Introduction}

Copper nanoparticles are widely used in modern catalysis. They are particularly attractive because of copper's high natural abundance, low cost and the multiple practical and straightforward ways of preparing Cu-based nanomaterials. They are used in the azide-alkyne cycloaddition process [1-3] and in the synthesis of 1,2,3-triazoles [4]. Due to their low cost, copper nanoparticles have successfully replaced catalysts based on noble and transition metals in Heck and Sonogashira reactions, as well as in the reactions of $\mathrm{C}-\mathrm{S}, \mathrm{C}-\mathrm{O}, \mathrm{C}-\mathrm{B}$, and $\mathrm{C}-\mathrm{Se}$ bonds formation [5-9]. In [10,11], copper was used as the main component of polymetallic catalysts. In [12,13], metal-organic and composite systems based on copper were considered. Despite numerous studies on Cu-based catalysts [14], this area of research still has many aspects that remain to be explored.

Due to the charge transfer between nanoparticles and the support, a local electric field of a sufficiently high strength of $10^{6}-10^{9} \mathrm{~V} / \mathrm{m}$ can exist close to the nanoparticle surface. The presence of such a field can affect the rate of chemical processes on the surface of the nanostructured coating. Indeed, the orientation of polar molecules induced by an electric field can lead to the synthesis of different products. The ability to control chemical reactions by electric fields was predicted in theory in [15], where the choice of orientation and direction of the field vis-à-vis the molecular axes was shown to drive the reaction in the direction 
of complete $\mathrm{C}-\mathrm{H}$ hydroxylation or complete $\mathrm{C}=\mathrm{C}$ epoxidation. This has been experimentally proven recently by an example of the Diels-Alder reaction, which was studied by the scanning tunneling microscopy (STM) break-junction method [16]. Previously, we found similar effects of the electric fields on the reduction of oxidized platinum by hydrogen [17], hydrogen adsorption on gold [18,19], decomposition of ammonia on organoboron [20] and platinum nanoparticles [21], and some reactions of the hydrogenation of hydrocarbons [22].

The methods and conditions used for the synthesis of nanoparticles mainly determine the possibilities of their further use. Therefore, it is important to accurately determine the characteristics of synthesized nanoparticles: their shape, size, and chemical composition [23,24]. Typically, catalysts are studied by standard methods, even in the case of nanostructured ones. Such methods provide information averaged over a large ensemble of nanoparticles, thus this approach practically does not allow the detection of differences between individual nanoparticles. To solve this problem, new approaches are required with local chemical sensitivity and high spatial and temporal resolution. These requirements are met by scanning probe methods, particularly by scanning tunneling microscopy and spectroscopy (STM/STS) methods [25-29]. By these methods, one can obtain the most detailed information on the structure and properties of nanostructured systems.

The aim of our work is to study the effect of $\mathrm{CO}$ orientation in an external electric field on the reduction of $\mathrm{Cu}$-based nanoparticles and the distribution of various oxide phases on the nanoparticle surface.

\section{Materials and Methods}

Nanoparticles were synthesized on the surface of highly oriented pyrolytic graphite (HOPG) with an angular spread of the $c$-axes of the crystallites of $0.8^{\circ}$ [30] by the impregnationprecipitation method. An aqueous solution of copper(II) nitrate $\mathrm{Cu}\left(\mathrm{NO}_{3}\right)_{2}$ with a concentration of $24 \mathrm{mg} / \mathrm{L}$ was used as a precursor. The precursor solution was applied to a cleaned surface of HOPG (AIST-NT, Moscow, Russia), which looked like vast atomically smooth $\mathrm{C}(0001)$ terraces. After drying the solution, the sample was placed in an STM chamber, where it was calcined under ultrahigh vacuum (UHV) conditions at a temperature of $750-850 \mathrm{~K}$ for $8 \mathrm{~h}$. The residual gas pressure did not exceed $2 \times 10^{-10} \mathrm{mbar}$. During the calcination, the precursor solution decomposed with the formation of copper(II) oxide and gaseous nitrogen(IV) oxide and oxygen, which were pumped out of the chamber. The decomposition of anhydrous copper(II) nitrate at atmospheric pressure is known to begin at a temperature of $440 \mathrm{~K}$ [31]. The precursor decomposition occurs:

$$
2 \mathrm{Cu}\left(\mathrm{NO}_{3}\right)_{2} \stackrel{t}{\rightarrow} 2 \mathrm{CuO}+4 \mathrm{NO}_{2}+\mathrm{O}_{2}
$$

The experiments were carried out with a scanning tunneling microscope (UHV VT STM, Omicron NanoTechnology, Taunusstein, Germany) under ultrahigh vacuum conditions. This allowed us to avoid uncontrolled changes in the chemical composition of the samples due to residual gases. The platinum-iridium STM tips used for the experiments were prepared by standard methods and treated by argon ion sputtering under UHV conditions. In the experiments, we used only those tips that showed reproducible volt-ampere characteristics (VAC) with S-shaped curves when scanning HOPG. Such VACs are typical for metal-metal tunnel nanocontacts [25-29].

The $\mathrm{CO}$ adsorption under $1 \times 10^{-6}$ mbar of pressure and the reduction of nanoparticles were studied at $300 \mathrm{~K}$ in the presence of an external oriented electric field. Before introducing the gas, the STM tip was removed $\sim 5 \mathrm{~mm}$ away from the surface of the sample, and during the adsorption experiment, the tip was fixed in this position. During exposure, a potential difference, $\Delta V$, was applied to the vacuum gap between the sample and the grounded tip. Thus, the system of the STM tip and sample surface forms an asymmetric capacitor, inside which an inhomogeneous electric field exists. Exposure of the samples to $\mathrm{CO}$ was carried out at two potential differences: $\Delta V=+1$ and $-1 \mathrm{~V}$ with respect to the grounded STM tip. After pumping CO out of the chamber, the potential difference was switched off, and STM spectroscopy experiments were performed to investigate the 
structure of $\mathrm{Cu}$-based nanoparticles modified by $\mathrm{CO}$. The exposure value was measured in Langmuir, $1 \mathrm{~L}=1.33 \times 10^{-6}$ mbar.s.

\section{Results and Discussion}

\subsection{Morphology, Local Electronic Structure and Chemical Composition}

The shape of copper nanoparticles in most cases was found to be close to spherical, and their diameter was about $10 \mathrm{~nm}$ (Figure 1). Most of the nanoparticles are agglomerated and form irregularly shaped clusters consisting of hundreds of nanoparticles. They are grouped near the boundaries of the graphene sheets that make up the surface of the support. About $20 \%$ of the sample surface is covered with nanoparticles.
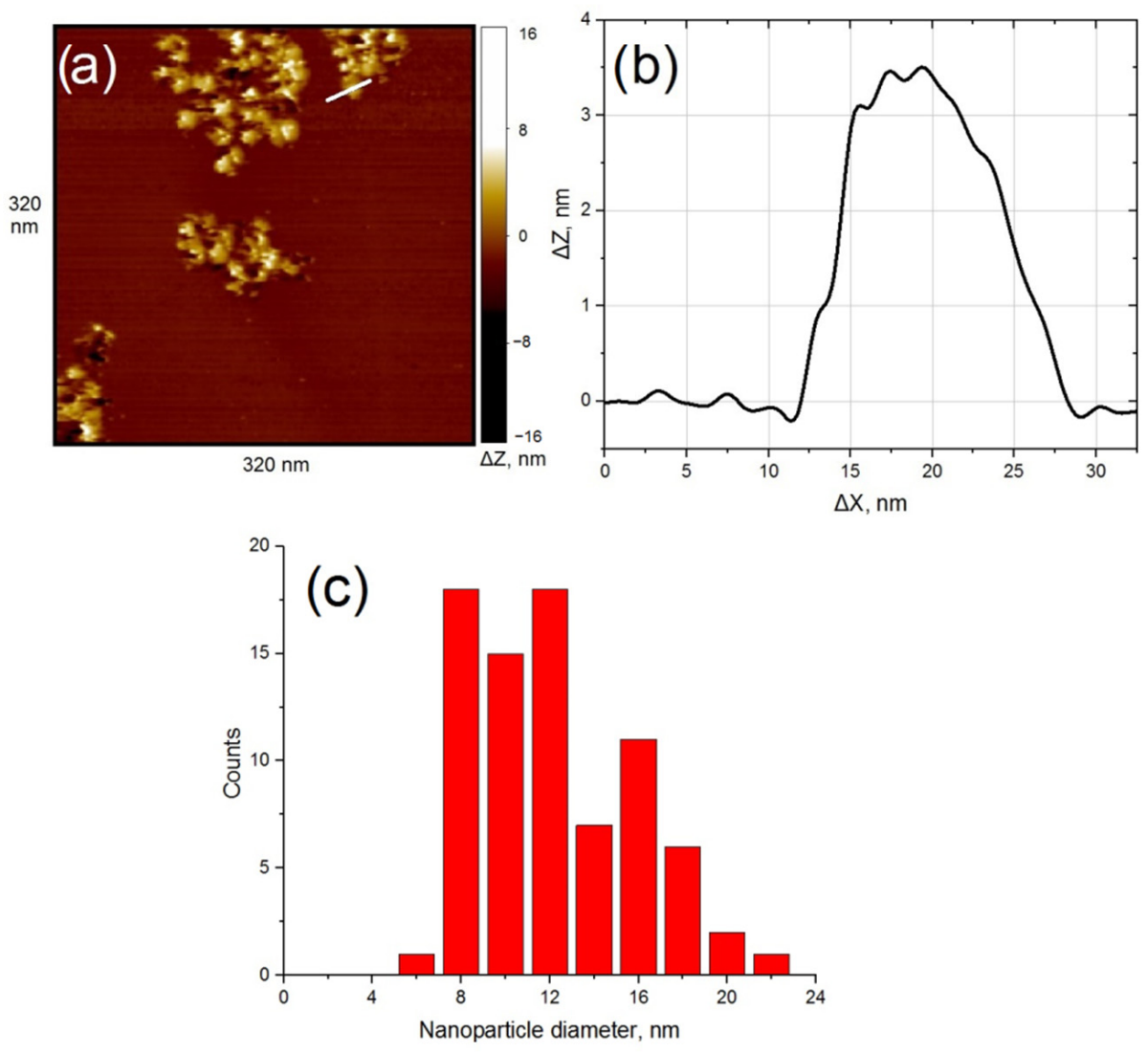

Figure 1. The sample after calcination under ultrahigh vacuum (UHV) conditions $(t=8 \mathrm{~h}$, $T=750-850 \mathrm{~K}$ ). Results of the scanning tunneling microscopy (STM) measurement: (a) topography image of highly oriented pyrolytic graphite (HOPG) surface with deposited clusters of Cu-based nanoparticles; (b) profile of the surface along the cut line shown in Figure 1a; (c) nanoparticle size distribution.

STM measurements have shown that the surface of the nanoparticles is rather inhomogeneous. The local electronic structure changes significantly even within the surface of a single nanoparticle. In general, we can say that the electronic structure of the nanoparticles corresponds to a semiconductor; that is, the nanoparticles consist of copper oxides, but in rare cases, there are areas of pure metal on the surface. Local nanocontact VACs, measured at different points of the nanoparticle surface, can be conventionally divided into four types. Figure 2 shows various types of VAC behavior. About 23\% of VAC curves correspond to Curve 1 . In these curves, the zero-current section ranges from 0 to $1.1 \mathrm{~V}$. This also includes surface areas with a metallic type of conductivity. Hereafter, the local electronic structure of this type will be denoted as $\mathrm{Cu}-1$. 


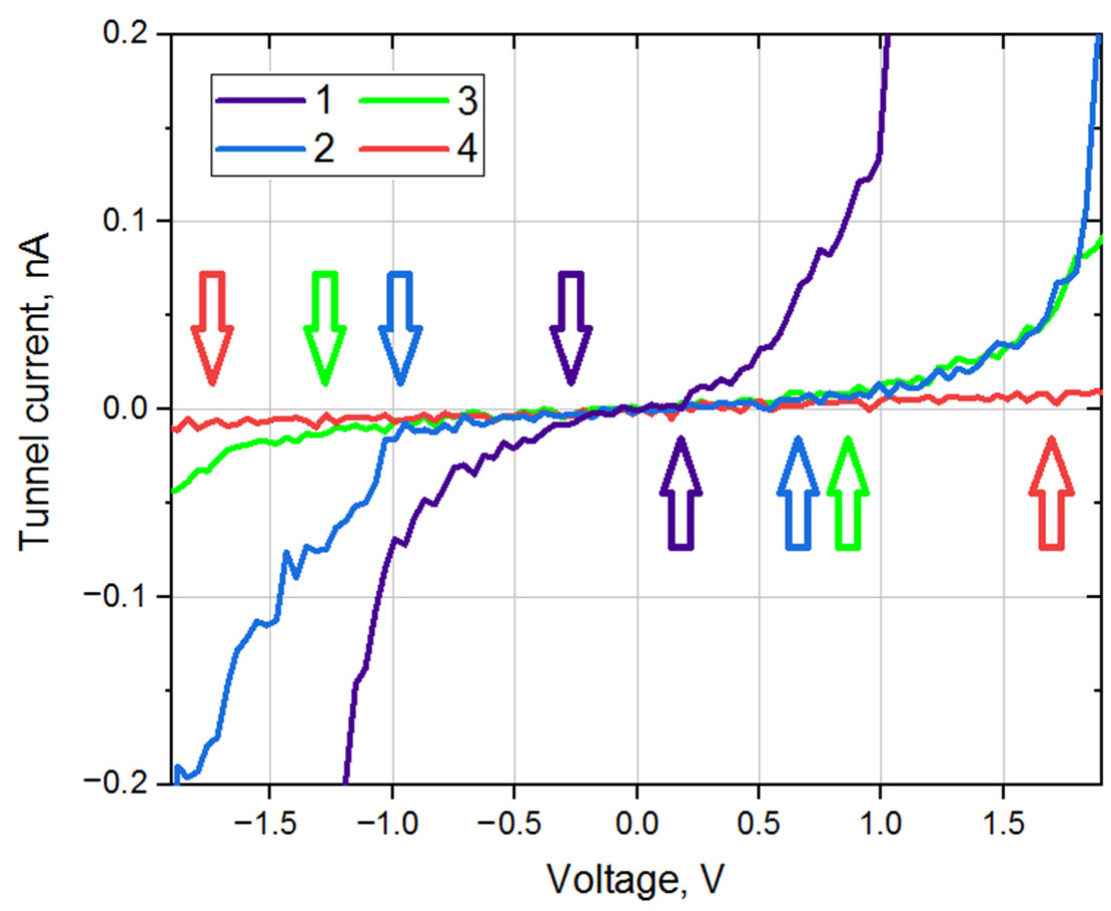

Figure 2. Types of local volt-ampere characteristic (VAC) curves, corresponding to various copper oxides. The edges of zero-current sections for various curves are marked with colored arrows.

Local VAC curves similar to Curve 2 in Figure 2 occur in $30 \%$ of cases. For such curves, the zero-current section is about 1.2-1.8 V. The electronic structure of the synthesized nanoparticles at these points on the surface corresponds to a semiconductor. This suggests that oxide is present at least on the surface of the nanoparticles. This type of electronic structure will be denoted as $\mathrm{Cu}-2$.

The VAC curves (Figure 2, Curve 3) with a section of zero-current of 2.2-2.8 V are found in $30 \%$ of cases. The surface of the nanoparticles at these points is also covered with oxide, but its characteristics differ from the previous ones. We will denote such a type of electronic structure as $\mathrm{Cu}-3$.

Finally, the VAC curves in $14 \%$ of cases demonstrate a zero-current section of $2.9 \mathrm{~V}$ and above (Figure 2, Curve 4). We will denote this type of electronic structure as $\mathrm{Cu}-4$. Additionally, we should say that VACs with a section of zero-current of $1.9-2.1 \mathrm{~V}$ practically do not occur (2-3\%) during all the experiments; therefore, hereafter, we will only talk about the four types of electronic structure listed above.

Since the width of the zero-current section corresponds to the band gap of the material under the STM tip up to a dimensional factor, one can conclude that the local electronic structure of $\mathrm{Cu}$-based nanoparticles deposited on HOPG belongs to one of four types: $\mathrm{Cu}-1$ with a small band gap (no more than $1.1 \mathrm{eV}$ ), $\mathrm{Cu}-2$ with a band gap of about 1.2-1.8 eV, Cu-3 with a band gap of about 2.2-2.8 eV, and Cu- 4 with a band gap of more than $2.9 \mathrm{eV}$. In Figure 2, the band gap edges for various VAC types are marked with colored arrows. The initial distribution of various types of local electronic structure over the surface of synthesized nanoparticles is shown in Figure 3a. 

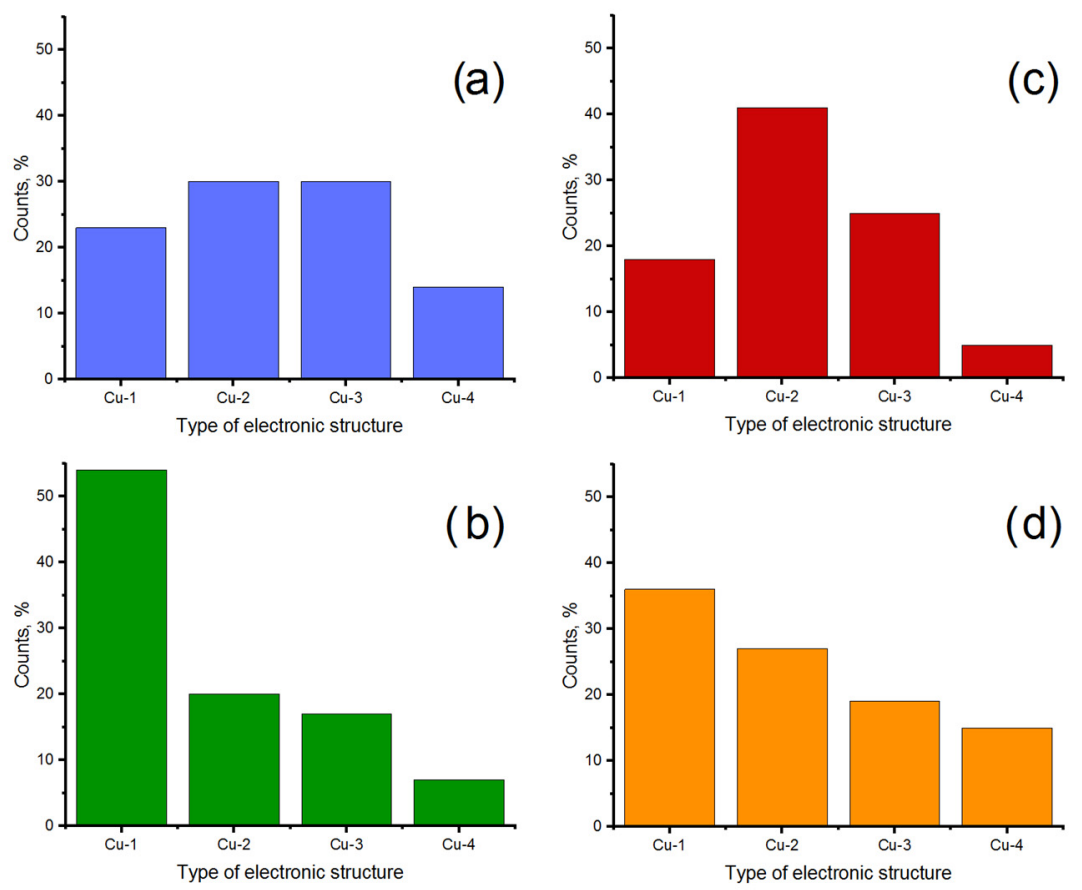

Figure 3. Ratio between various types of local electronic structure on the surface of nanoparticles: (a) after calcination and precursor decomposition; (b) after exposure to CO (400 L, T=300 K, $\Delta V=-1 \mathrm{~V})$; (c) after oxidation in $\operatorname{air}(t=40 \mathrm{~h}, T=300 \mathrm{~K})$; (d) after exposure to CO $(400 \mathrm{~L}, T=300 \mathrm{~K}$, $\Delta V=+1 \mathrm{~V})$. To obtain each histogram, at least 50 counts were performed.

The results obtained can be compared with known data and the local chemical composition of various surface areas can be analyzed. The electronic structure of $\mathrm{CuO}, \mathrm{Cu}_{2} \mathrm{O}$ and $\mathrm{Cu}_{4} \mathrm{O}_{3}$ copper oxides is considered in a number of works [32-37]. According to them, all these oxides are semiconductors, and $\mathrm{Cu}_{2} \mathrm{O}$ has the largest band gap of 2.17-2.62 eV [33], and the band gaps of $\mathrm{CuO}$ and $\mathrm{Cu}_{4} \mathrm{O}_{3}$ are in the range of 1.35-1.7 eV [33-37]. One can conclude that the electronic structure of the type $\mathrm{Cu}-2$ corresponds to a mixture of $\mathrm{CuO}$ and $\mathrm{Cu}_{4} \mathrm{O}_{3}$ oxides, the electronic characteristics of which are similar. The local chemical composition of the surface areas with an electronic structure of the type $\mathrm{Cu}-3$ corresponds to the $\mathrm{Cu}_{2} \mathrm{O}$ oxide. This conclusion is also confirmed by the fact that during all the experiments, practically no surface areas with a local band gap of 1.9-2.1 eV were found. Thus, a mixture of $\mathrm{CuO}$ and $\mathrm{Cu}_{4} \mathrm{O}_{3}$ oxides always differs from $\mathrm{Cu}_{2} \mathrm{O}$ in spectroscopy.

Oxide structures of the type $\mathrm{Cu}-1$ on the surface of the nanoparticles do not have an exact correspondence with the known stable copper oxides. The known band gap values in this case exceed the observed ones. This situation can be realized in the case of the formation of a very thin oxide layer on the metal or a low content of oxygen atoms in the oxide ( $<0.5$ at.O/at.Cu). In the case of $\mathrm{Cu}-4$, apparently, the observed band gap is associated not with the chemical composition of the formed oxide, but with its high defectiveness. One should remember that the electronic structure of the nanoparticles can be strongly distorted due to interaction with substrate defects, the electronic structure of which is also very different from the electronic structure of a defect-free graphite surface [38].

\subsection{CO Adsorption Experiments in Presence of External Electric Field}

Since the CO molecule is polar, one can assume that the electric field inside the asymmetric capacitor formed by the STM tip and the sample surface can affect the orientation of the $\mathrm{CO}$ molecule. Therefore, by changing the direction of the electric field, it is possible to prevent or promote the reduction of copper on the surface of nanoparticles. In this case, due to the small radius of curvature $\left(\rho \sim 10^{-9} \mathrm{~m}\right)$, the strength of the local electric field, $E$, near the surface of nanoparticles can be very high $(\rho E=$ const). To test this assumption, we 
performed a $\mathrm{CO}$ adsorption experiment, during which the potential difference, $\Delta V=+1$, or $-1 \mathrm{~V}$, was applied to the vacuum gap between the grounded tip and the sample.

The exposure of the sample to $\mathrm{CO}(400 \mathrm{~L})$ at a potential $\Delta V=-1 \mathrm{~V}$ does not influence the size of the nanoparticles or their spatial distribution, but significantly changes the electronic structure of the nanoparticle surface. One can see that the ratio between various types of local electronic structure changes dramatically (Figure 3b): $\mathrm{Cu}-1$ increases to $54 \%$; and other types- $\mathrm{Cu}-2, \mathrm{Cu}-3$ and $\mathrm{Cu}-4-$ decrease to $20 \%, 17 \%$ and $7 \%$, respectively. At the same time, among the VAC curves, a large proportion without a zero-current section is found (included in $\mathrm{Cu}-1$ ). That is, a partial reduction of copper occurs on the surface of nanoparticles. This is consistent with the results of [39], where it was noted that the complete reduction of oxidized copper in $\mathrm{CO}$ can occur even at a relatively low temperature of $473 \mathrm{~K}$.

Exposure of the sample to air ( $40 \mathrm{~h}$ ) again significantly changed the electronic structure of the surface (Figure 3c): the content of $\mathrm{Cu}-1$ decreased to $18 \%$; $\mathrm{Cu}-2$ and $\mathrm{Cu}-3$ increased to $41 \%$ and $25 \%$, respectively; and $\mathrm{Cu}-4$ practically did not change (5\%). It should be noted that the system obtained by oxidation in atmospheric oxygen is somewhat different from the system obtained by precursor thermal decomposition in UHV. Apparently, the reason for this is that during the thermal decomposition of the precursor, the formation of oxide phases occurs in parallel. Since all oxygen and nitrogen oxides are immediately pumped out from the system, these reactions can be considered quasi-independent. However, during oxidation in the atmosphere, oxide phases are formed sequentially under conditions of excessive oxygen content. In this case, the oxides $\mathrm{Cu}_{2} \mathrm{O}$ and $\mathrm{Cu}_{4} \mathrm{O}_{3}$ are intermediate products, and their concentration will strongly depend on the concentrations of all other Cu-based phases:

$$
\mathrm{Cu} \stackrel{+\mathrm{O}_{2}}{\rightarrow} \mathrm{Cu}_{2} \mathrm{O} \stackrel{+\mathrm{O}_{2}}{\rightarrow} \mathrm{Cu}_{4} \mathrm{O}_{3} \stackrel{+\mathrm{O}_{2}}{\rightarrow} \mathrm{CuO}
$$

This assumption is consistent with the results of [40], from which it follows that the $\mathrm{Cu}_{4} \mathrm{O}_{3}$ or $\mathrm{Cu}_{2} \mathrm{O}$ oxides can be both intermediate and independent products of reactions of copper and its oxides with gases.

After STM measurements, the sample was, again, exposed to CO (400 L). During exposure, a potential difference $\Delta V=+1 \mathrm{~V}$ was applied to the vacuum gap. At this stage, the electronic structure of the sample surface was rearranged again (Figure $3 \mathrm{~d}$ ): the content of $\mathrm{Cu}-1$ increased to $36 \%$, and $\mathrm{Cu}-2$ and $\mathrm{Cu}-3$ decreased to $27 \%$ and $19 \%$, respectively. The content of $\mathrm{Cu}-4$ increased slightly to $15 \%$.

\subsection{Simulation}

Since $\mathrm{Cu}-1$ corresponds to metallic copper and unstable oxides with a low oxygen content $(<0.5$ at. $\mathrm{O} / \mathrm{at} . \mathrm{Cu})$, the content of $\mathrm{Cu}-1$ in the system can be taken as a measure of reduction efficiency. Comparing the state of the system after reduction at various potential differences applied to the vacuum gap, one can note that when the potential difference $\Delta V=-1 \mathrm{~V}$ is applied, reduction is more efficient: the content of compounds with an electronic structure of the $\mathrm{Cu}-1$ type in this case increases from $23 \%$ to $55 \%$, while at the positive potential, from $18 \%$ to $36 \%$.

Initially, it was assumed that the orientation of the $\mathrm{CO}$ molecule with its carbon end to the nanoparticle surface should facilitate copper reduction. The obtained result is consistent with this assumption. Indeed, at $\Delta V=-1 \mathrm{~V}$, the sample is negatively charged, and the $\mathrm{CO}$ molecule is turned towards the nanoparticle surface by a carbon atom, on which there is a partial positive charge $\delta+$.

According to [41], the reduction of copper oxides in CO can vary considerably with experimental conditions (gas flow rate, temperature, sample size, etc.), and its complex kinetics cannot be described by a single n-order expression over the entire range of the 
reaction. In order to make simple estimations, it is enough to consider this process as a complex reaction proceeding according to the scheme [39]:

$$
\mathrm{Cu} \text { ox }+\mathrm{CO} \underset{k_{2}}{\stackrel{k_{1}}{\rightarrow}} \mathrm{Cu} \text { ox }(\mathrm{CO}) \stackrel{k_{3}}{\rightarrow} \mathrm{Cu} \text { red }+\mathrm{CO}_{2}
$$

where $k_{1}, k_{2}$, and $k_{3}$ are reaction rate constants; $C u_{\text {red }}$ are compounds with electronic structure of type $\mathrm{Cu}-1$; and $C u_{o x}$ are compounds with electronic structure of types $\mathrm{Cu}-2, \mathrm{Cu}-$ 3 and $\mathrm{Cu}-4$. The analytical solution of a system of differential equations corresponding to a given reaction scheme allows the concentration of the $C u_{\text {red }}$ product to be expressed [42]:

$$
\begin{gathered}
\Delta C_{r e d}=C_{o x}^{0}\left[1-\frac{\alpha+\beta}{2 \beta} \exp \left(-\frac{\alpha-\beta}{2} t\right)+\frac{\alpha-\beta}{2 \beta} \exp \left(-\frac{\alpha+\beta}{2} t\right)\right], \\
\alpha=k_{1} C_{C O}+k_{2}+k_{3}, \beta=\sqrt{\alpha^{2}-4 C_{C O} k_{1} k_{3}}
\end{gathered}
$$

where $C_{\text {red }}$ is the concentration of compounds with electronic structure of type $\mathrm{Cu}-1, C_{C O}$ is the concentration of $\mathrm{CO}$ molecules turned with a carbon end to a nanoparticle, and $C_{o x}^{0}$ is the initial concentration of all copper oxide phases except $\mathrm{Cu}-1$ in the system. Expression (4a) describes not the $C_{\text {red }}$ as it is, but the difference between its final and initial values. The reason for such a result is that Expression (4a) is obtained under the assumption that the final stage of the reaction is irreversible, as $\mathrm{CO}_{2}$ is being pumped out of the system during the reaction. Thus, the $\mathrm{CO}_{2}$ concentration and initial concentration of metal copper would not influence the reaction rate. The $C_{C O}$ remains constant during the experiment. Work [39] makes it possible to estimate the values of $k_{1}, k_{2}$ and $k_{3}$ for processes involving $\mathrm{CuO}$ or $\mathrm{Cu}_{2} \mathrm{O}$ at room temperature (Table 1 ).

Table 1. Values of $k_{1}, k_{2}$ and $k_{3}$ for processes involving $\mathrm{CuO}$ or $\mathrm{Cu}_{2} \mathrm{O}$ at room temperature according to [39].

\begin{tabular}{cccc}
\hline & $k_{\mathbf{1}}, \mathbf{m}^{\mathbf{3}} \cdot \mathbf{m o l}^{\mathbf{- 1}} \cdot \mathbf{s}^{\mathbf{- 1}}$ & $k_{\mathbf{2}}, \mathbf{s}^{\mathbf{- 1}}$ & $k_{3}, \mathbf{s}^{\mathbf{- 1}}$ \\
\hline $\mathrm{CuO} \rightarrow \mathrm{Cu}$ & $10^{-5}$ & $10^{-1}$ & 1 \\
$\mathrm{Cu} u_{2} \mathrm{O} \rightarrow \mathrm{Cu}$ & $10^{-7}$ & $10^{-1}$ & $10^{-4}$ \\
\hline
\end{tabular}

For both reactions, $C_{C O} \approx 5 \times 10^{-8} \mathrm{~mol} / \mathrm{m}^{3}, t \approx 400 \mathrm{~s}$, and $k_{1} C_{C O}<<k_{2}, k_{3}$; therefore, we can write the following:

$$
\begin{gathered}
\frac{\alpha-\beta}{2 \beta} \approx \frac{k_{1} C_{\mathrm{CO}}}{k_{2}+k_{3}}, \\
\frac{\alpha+\beta}{2 \beta} \approx 1, \\
\exp \left(-\frac{\alpha-\beta}{2} t\right) \approx 1-\frac{k_{1} C_{C O}}{2}, \\
\frac{\alpha-\beta}{2 \beta} \exp \left(-\frac{\alpha+\beta}{2} t\right) \rightarrow 0
\end{gathered}
$$

As a result, we obtain the following:

$$
\Delta C_{r e d} \sim C_{o x}^{0} C_{C O} k_{1} t
$$

Since the reaction $\mathrm{Cu}_{2} \mathrm{O} \leftrightarrow \mathrm{CuO}+\mathrm{Cu}$ practically does not occur [39], the reduction processes of $\mathrm{CuO}$ and $\mathrm{Cu}_{2} \mathrm{O}$ can be considered separately; that is, Expression (6) is valid regardless of the chemical composition of the oxide. In this case, the experimental results can be described by a simple two-level model, in which $\mathrm{CO}$ molecules can be oriented 
"along the field" and "against the field". If the ground state of the CO molecule is considered to be orientated "along the field", we obtain:

$$
\mathrm{C}_{\mathrm{CO}+}=\mathrm{C}_{\mathrm{CO}-} \times \exp \left(-\frac{E d}{k_{B} T}\right)
$$

where $k_{B}$ is the Boltzmann constant; $E$ is the electric field strength close to the surface of the nanoparticle; $d$ is the electric dipole moment of the $\mathrm{CO}$ molecule; $\mathrm{C}_{\mathrm{CO}-}$ and $\mathrm{C}_{\mathrm{CO}+}$ are the concentrations of $\mathrm{CO}$ molecules oriented "along the field" and "against the field", respectively. One can assume that in the case of a negative potential $\Delta V=-1 \mathrm{~V}$, reduction occurs only due to the molecules turned by their carbon end to the nanoparticle oriented "along the field". In the case of a positive potential $\Delta V=+1 \mathrm{~V}$, everything happens the other way: reduction occurs only due to the disoriented molecules. Before exposure to $\mathrm{CO}$, the initial concentration of $C_{o x}^{0}$ in the systems is approximately the same: 0.77 in the case of $\Delta V=-1 \mathrm{~V}$ and 0.82 in the case of $\Delta V=+1 \mathrm{~V}$. The concentration here is the relative content of this oxide phase (Figure $3 \mathrm{a}, \mathrm{c}$ ). Therefore, the following is valid:

$$
\frac{\Delta C_{r e d+}}{\Delta C_{r e d-}} \approx \frac{C_{C O+}}{C_{C O-}}=\exp \left(-\frac{E d}{k_{B} T}\right)
$$

where $\Delta C_{\text {red- }}$ and $\Delta C_{\text {red+ }}$ are the changes in concentrations of compounds with electronic structure of the type $\mathrm{Cu}-1$, when the potential difference is positive and negative correspondingly. Since $d$ is $0.4 \times 10^{-30} \mathrm{C} \cdot \mathrm{m}$ for $\mathrm{CO}$ molecule, $C_{\text {red- }}$ changes from 0.23 to 0.54 , and $C_{\text {red }+}$ changes from 0.18 to 0.36 (Figure $3 b, d$ ), one can estimate the strength of the electric field required for the orientation effect to be observed:

$$
E=-\frac{k_{B} T}{d} \ln \left(\frac{\Delta C_{r e d+}}{\Delta C_{r e d-}}\right) \approx 6 \times 10^{9} \mathrm{~V} / \mathrm{m}
$$

The obtained value is consistent with the assumption of a strong electric field close to the surface of nanoparticles and with the results of works [19,43].

Thus, the orientation of the $\mathrm{CO}$ molecule with the carbon end to the nanoparticle promotes the reduction of copper in $\mathrm{CuO}, \mathrm{Cu}_{4} \mathrm{O}_{3}$, and $\mathrm{Cu}_{2} \mathrm{O}$ oxide systems. Since the key factor affecting the local electric field strength is the characteristic size of the elements of the nanostructured coating, this effect can be observed in weak electric fields if the nanoparticle size is $1-10 \mathrm{~nm}$.

\section{Conclusions}

The experiments described above have demonstrated the possibility of controlling the adsorption of polar molecules on the surface of nanoparticles by means of an external electric field. STM/STS methods have been successfully used to study the adsorption of $\mathrm{CO}$ on $\mathrm{Cu}$-based nanoparticles deposited on the surface of highly oriented pyrolytic graphite. It was shown that the orientation of the $\mathrm{CO}$ molecule with the carbon end to the nanoparticle promotes metal reduction. When the potential difference $\Delta V=-1 \mathrm{~V}$ is applied to the sample with respect to the grounded STM tip, the exposure of the sample to $\mathrm{CO}\left(T=300 \mathrm{~K}\right.$ and $\left.P=1 \times 10^{-6} \mathrm{mbar}\right)$ is accompanied by $\mathrm{CO}$ adsorption and subsequent copper reduction. In the case of $\Delta V=+1 \mathrm{~V}, \mathrm{CO}$ adsorption and copper reduction efficiency decrease. This result is well described by the two-level model. The performed estimates of the electric field strength confirm that the orientation effect manifests itself close to the surface of nanoparticles with a radius of curvature of $\sim 10^{-9} \mathrm{~m}$.

Author Contributions: Conceptualization, S.Y.S.; methodology, S.Y.S. and A.K.G.; formal analysis, S.A.O.; investigation, A.K.G. and N.V.D.; writing-original draft preparation, V.A.K. and N.V.D.; writing-review and editing, S.Y.S.; visualization, S.A.O. and V.A.K.; supervision, B.R.S.; project administration, M.V.G.; funding acquisition, B.R.S. All authors have read and agreed to the published version of the manuscript. 
Funding: This research was funded by the Russian Foundation for Basic Research (RFBR), project No. 20-03-00419.

Data Availability Statement: The data presented in this study are available on request from the corresponding author.

Conflicts of Interest: The authors declare no conflict of interest. The funders had no role in the design of the study; in the collection, analyses, or interpretation of data; in the writing of the manuscript, or in the decision to publish the results.

\section{References}

1. Amblard, F.; Cho, J.H.; Schinazi, R.F. Cu(I)-Catalyzed Huisgen Azide-Alkyne 1,3-Dipolar Cycloaddition Reaction in Nucleoside, Nucleotide, and Oligonucleotide Chemistry. Chem. Rev. 2009, 109, 4207-4220. [CrossRef] [PubMed]

2. Meldal, M.; Tornøe, C.W. Cu-Catalyzed Azide-Alkyne Cycloaddition. Chem. Rev. 2008, 108, 2952-3015. [CrossRef] [PubMed]

3. Baig, R.B.N.; Varma, R.S. Copper on Chitosan: A Recyclable Heterogeneous Catalyst for Azide-Alkyne Cycloaddition Reactions in Water. Green Chem. 2013, 15, 1839-1843. [CrossRef]

4. Alonso, F.; Moglie, Y.; Radivoy, G.; Yus, M. Click Chemistry from Organic Halides, Diazonium Salts and Anilines in Water Catalysed by Copper Nanoparticles on Activated Carbon. Org. Biomol. Chem. 2011, 9, 6385-6395. [CrossRef]

5. Kim, J.H.; Chung, Y.K. Copper Nanoparticle-Catalyzed Borylation of Alkyl Bromides with an Organodiboron Compound. RSC Adv. 2014, 4, 39755-39758. [CrossRef]

6. Nador, F.; Fortunato, L.; Moglie, Y.; Vitale, C.; Radivoy, G. A Simple One-Pot Procedure for the Direct Homocoupling of Terminal Alkynes Promoted by Copper Nanoparticles. Synthesis 2009, 2009, 4027-4031. [CrossRef]

7. Sakoda, K.; Mihara, J.; Ichikawa, J. Heck-Type 5-Endo-Trig Cyclization Promoted by Vinylic Fluorines: Synthesis of 5-Fluoro-3HPyrroles. Chem. Commun. 2005, 37, 4684-4686. [CrossRef]

8. Kou, J.H.; Saha, A.; Bennett-Stamper, C.; Varma, R.S. Inside-Out Core-Shell Architecture: Controllable Fabrication of Cu $2 \mathrm{O} @ \mathrm{Cu}$ with High Activity for the Sonogashira Coupling Reaction. Chem. Commun. 2012, 48, 5862-5864. [CrossRef]

9. Khalilzadeh, M.A.; Keipour, H.; Hosseini, A.; Zareyee, D. KF/Clinoptilolite, an Effective Solid Base in Ullmann Ether Synthesis Catalyzed by CuO Nanoparticles. New J. Chem. 2014, 38, 42-45. [CrossRef]

10. Chung-Hsin, L.; Chung-Han, L.; Chung-Hsien, W. Microemulsion-mediated Solvothermal Synthesis of Copperindiumdiselenide Powders. Sol. Energy Mater. Sol. Cells 2010, 94, 1622-1626. [CrossRef]

11. Marella, R.K.; Neeli, C.K.P.; Kamaraju, S.R.R.; Burri, D.R. Highly Active Cu/MgO Catalysts for Selective Dehydrogenation of Benzyl Alcohol into Benzaldehyde Using Neither $\mathrm{O}_{2}$ Nor $\mathrm{H}_{2}$ Acceptor. Catal. Sci. Technol. 2012, 2, 1833-1838. [CrossRef]

12. Dhakshinamoorthy, A.; Hermenegildo, G. Metal-organic Frameworks as Solid Catalysts for the Synthesis of Nitrogen-Containing Heterocycles. Chem. Soc. Rev. 2014, 43, 5750-5765. [CrossRef] [PubMed]

13. Pham, L.Q.; Sohn, J.H.; Kim, C.W.; Park, J.H.; Kang, H.S.; Lee, B.C.; Kang, Y.S. Copper Nanoparticles Incorporated with Conducting Polymer: Effects of Copper Concentration and Surfactants on the Stability and Conductivity. J. Colloid Interface Sci. 2012, 365, 103-109. [CrossRef] [PubMed]

14. Gawande, M.B.; Goswami, A.; Felpin, F.-X.; Asefa, T.; Huang, X.; Silva, R.; Zou, X.; Zboril, R.; Varma, R.S. Cu and Cu-Based Nanoparticles: Synthesis and Applications in Catalysis. Chem. Rev. 2016, 116, 3722-3811. [CrossRef] [PubMed]

15. Shaik, S.; de Visser, S.P.; Kumar, D. External electric field will control the selectivity of enzymatic-like bond activations. J. Am. Chem. Soc. 2004, 126, 11746-11749. [CrossRef]

16. Aragonès, A.C.; Haworth, N.L.; Darwish, N.; Ciampi, S.; Bloomfield, N.J.; Wallace, G.G.; Diez-Perez, I.; Coote, M.L. Electrostatic catalysis of a Diels-Alder reaction. Nature 2016, 531, 88-91. [CrossRef]

17. Balashov, E.M.; Gatin, A.K.; Grishin, M.V.; Dalidchik, F.I.; Kolchenko, N.N.; Shub, B.R. The influence of strong electric fields on the growth of platinum oxide nanoparticles and their interaction with molecular hydrogen. Russ. J. Phys. Chem. B 2010, 4, 340-345. [CrossRef]

18. Gatin, A.K.; Grishin, M.V.; Kolchenko, N.N.; Sarvadii, S.Y.; Shub, B.R. Effect of the Electric Potential on the Interaction of Gold Nanoparticles Deposited on a Graphite Substrate with Molecular Hydrogen. Russ. J. Phys. Chem. B 2017, 11, 370-374. [CrossRef]

19. Sarvadiy, S.Y.; Gatin, A.K.; Grishin, M.V.; Kharitonov, V.A.; Kolchenko, N.N.; Dokhlikova, N.V.; Shub, B.R. Electric field-prevented adsorption of hydrogen on supported gold nanoparticles. Gold Bull. 2019, 52, 61-67. [CrossRef]

20. Grishin, M.V.; Gatin, A.K.; Slutskii, V.G.; Kharitonov, V.A.; Tsyganov, S.A.; Shub, B.R. Effect of the electric potential of organoboron nanoparticles on their catalytic activity in the decomposition of ammonia. Russ. J. Phys. Chem. B 2016, 10, 538-542. [CrossRef]

21. Grishin, M.V.; Gatin, A.K.; Slutskii, V.G.; Kharitonov, V.A.; Tsyganov, S.A.; Shub, B.R. Ammonia decomposition on a platinum nanocoating at various electric potentials. Russ. J. Phys. Chem. B 2016, 10, 760-763. [CrossRef]

22. Korchak, V.N.; Grishin, M.V.; Bykhovskii, M.Y.; Gatin, A.K.; Slutskii, V.G.; Kharitonov, V.A.; Tsyganov, S.A.; Shub, B.R. Ethylene Hydrogenation on a Platinum Nanocoating at Various Electric Potentials. Russ. J. Phys. Chem. B 2017, 11, 932-936. [CrossRef]

23. Roldan Cuenya, B. Synthesis and catalytic properties of metal nanoparticles: Size, shape, support, composition, and oxidation state effects. Thin Solid Films 2010, 518, 3127-3150. [CrossRef]

24. Umer, A.; Naveed, S.; Ramzan, N.; Rafique, M.S. Selection of a Suitable Method for the Synthesis of Copper Nanoparticles. NANO Brief Rep. Rev. 2012, 7, 1230005. [CrossRef] 
25. Güntherodt, H.J.; Wiesendanger, R. (Eds.) Scanning Tunneling Microscopy I: General Principles and Applications to Clean and Absorbate-Covered Surfaces; Springer: Berlin, Germany, 1994; p. 280. [CrossRef]

26. Binnig, G.; Rohrer, H.; Berber, C.; Weibel, E. Tunneling through a controllable vacuum gap. Appl. Phys. Lett. 1982, 40, 178-180. [CrossRef]

27. Meyer, E.; Hug, H.J.; Bennewitz, R. (Eds.) Scanning Probe Microscopy; Springer: Berlin/Heidelberg, Germany, $2004 ;$ p. 210. [CrossRef]

28. Hamers, R.J.; Wang, Y.J. Atomically-resolved studies of the chemistry and bonding at silicon surfaces. Chem. Rev. 1996, 96, 1261-1290. [CrossRef] [PubMed]

29. Hamers, R.J.; Tromp, R.M.; Demuth, J.E. Surface electronic structure of Si (111)-(7×7) resolved in real space. Phys. Rev. Lett. 1986, 56, 1972-1975. [CrossRef] [PubMed]

30. Fitzer, E.; Kochling, K.-H.; Boehm, H.P.; Marsh, H. Recommended terminology for the description of carbon as a solid (IUPAC recommendations 1995). Pure Appl. Chem. 1995, 67, 473-506. [CrossRef]

31. Kirsankin, A.A.; Grishin, M.V.; Sarvadii, S.Y.; Zamota, P.F.; Shub, B.R. Physicochemical Properties of Copper Nanoparticles Synthesized by the Different Methods. Russ. J. Phys. Chem. B 2017, 11, 521-525. [CrossRef]

32. Heinemann, M.; Eifert, B.; Heiliger, C. Band structure and phase stability of the copper oxides $\mathrm{Cu}_{2} \mathrm{O}, \mathrm{CuO}$, and $\mathrm{Cu}_{4} \mathrm{O}_{3}$. Phys. Rev. B 2013, 87, 115111. [CrossRef]

33. Meyer, B.K.; Polity, A.; Reppin, D.; Becker, M.; Hering, P.; Klar, P.J.; Sander, T.; Reindl, C.; Benz, J.; Eickhoff, M.; et al. Binary copper oxide semiconductors: From materials towards devices. Phys. Status Solidi B 2012, 249, 1487-1647. [CrossRef]

34. Ghijsen, J.; Tjeng, L.H.; van Elp, J.; Eskes, H.; Westerink, J.; Sawatzky, G.A.; Czyzyk, M.T. Electronic structure of Cu $2 \mathrm{O}$ and CuO Phys. Rev. B 1988, 38, 11322-11330. [CrossRef] [PubMed]

35. Koffyberg, F.P.; Benko, F.A. A photoelectrochemical determination of the position of the conduction and valence band edges of p-type CuO. J. Appl. Phys. 1982, 53, 1173-1177. [CrossRef]

36. Marabelli, F.; Parravicini, G.B.; Salghetti-Drioli, F. Optical gap of CuO. Phys. Rev. B 1995, 52, 1433-1436. [CrossRef]

37. Pierson, J.F.; Thobor-Keck, A.; Billard, A. Cuprite, paramelaconite and tenorite films deposited by reactive magnetron sputtering. Appl. Surf. Sci. 2003, 210, 359-367. [CrossRef]

38. Balashov, E.M.; Dalidchik, F.I.; Shub, B.R. Structure and electronic properties of imperfect oxides and nanooxides. Russ. J. Phys. Chem. B 2008, 2, 840-855. [CrossRef]

39. Goldstein, E.A.; Mitchell, R.E. Chemical kinetics of copper oxide reduction with carbon monoxide. Proc. Combust. Inst. 2011, 33, 2803-2810. [CrossRef]

40. Kim, J.Y.; Rodriguez, J.A.; Hanson, J.C.; Frenkel, A.I.; Lee, P.L. Reduction of $\mathrm{CuO}$ and $\mathrm{Cu}_{2} \mathrm{O}$ with $\mathrm{H}_{2}$ : $\mathrm{H}$ embedding and kinetic effects in the formation of suboxides. J. Am. Chem. Soc. 2003, 125, 10684-10692. [CrossRef]

41. Wang, X.; Hanson, J.C.; Frenkel, A.I.; Kim, J.-Y.; Rodriguez, J.A. Time-resolved Studies for the Mechanism of Reduction of Copper Oxides with Carbon Monoxide: Complex Behavior of Lattice Oxygen and the Formation of Suboxides. J. Phys. Chem. B 2004, 108, 13667-13673. [CrossRef]

42. Atkins, P.W.; de Paula, J. Physical Chemistry, 8th ed.; W.H. Freeman and Company: New York, NY, USA, 2006 ; p. 1085.

43. Zhang, Y.; Pluchery, O.; Caillard, L.; Lamic-Humblot, A.-F.; Casale, S.; Chabal, Y.J.; Salmeron, M. Sensing the charge state of single gold nanoparticles via work function measurements. Nano Lett. 2015, 15, 51-55. [CrossRef] 